\title{
ANALISIS END USER COMPUTER SATISFACTION SISTEM PEMBUATAN E-KTP DI KECAMATAN KARTASURA KABUPATEN SUKOHARJO
}

\author{
Novia Titis Sulistyani ${ }^{1)}$, Sri Siswanti ${ }^{2)}$, Setyowati $^{3)}$ \\ ${ }^{1)}$ Program Studi Sistem Informasi, STMIK Sinar Nusantara Surakarta \\ ${ }^{2)}$ Program Studi Teknik Informatika, STMIK Sinar Nusantara Surakarta \\ ${ }^{3)}$ Progarm Studi Manajemen Informatika, STMIK Sinar Nusantara Surakarta \\ ${ }^{1)}$ noviatitis1@gmail.com, ${ }^{2)}$ syswanty@ sinus.ac.id, ${ }^{3)}$ setyowati@sinus.ac.id
}

\begin{abstract}
The e-ID card service in Kecamatan Kartasura, Sukoharjo District has been running well, but people feel less satisfied with the service of making e-ID card by the sub-district officer. So it is necessary to know what factors affect the dissatisfaction. The research titled End User Computer Satisfaction analysis of e-ID card system in Kecamatan Kartasura Sukoharjo District was conducted to evaluate e-ID card making system in Kecamatan Kartasura Sukoharjo District.

Factors in the process of making e-ID card is the influence of perception of content, accuracy, ease, and influence of timely perception toward the satisfaction of society. The method used in this system analysis is End User Computer Satisfaction. Population and sample of the research are 120 population in Kecamatan Kartasura Sukoharjo District. The result of the questionnaires is analyzed by using SPSS 15 with the classical assumption test, multiple linear regression, coefficient of determination and T-test and F-test.

The results of the analysis revealed that $58.6 \%$ of the 4 independent variables of content, ease and timely affect the satisfaction of the population, while the accuracy does not affect the satisfaction of the population about the e-ID card system.
\end{abstract}

Keywords: e-ID card, EUCS, SPSS, Classic assumption test, T-test, F-test

\section{PENDAHULUAN}

Elektronik KTP (e-KTP) merupakan kartu identitas warga Negara Indonesia. Pada proses pembuatannya tidak dapat dilihat dari proses kesederhanaan, tetapi menempatkan posisi para petugas untuk melayani dan memberikan pelayanan kepada masyarakat. Program pembuatan e-KTP ini adalah langkah maju dari pemerintah Indonesia yang dimaksudkan untuk pendataan penduduk Indonesia yang tersebar di berbagai pulau di Indonesia. Sehingga program pembuatan e-KTP dengan menggunakan TI ini menjadikan pemerintah lebih mudah dalam pendataan penduduk.

KTP Elektronik adalah dokumen kependudukan yang memuat sistem keamanan / pengendalian baik dari sisi administrasi ataupun teknologi informasi dengan berbasis pada database kependudukan nasional. Dengan tujuan untuk mewujudkan kepemilikan satu identitas (KTP) untuk satu penduduk yang memiliki kode keamanan dan rekaman elektronik data kependudukan berbasis NIK secara Nasional. (biodata, foto, sidik jari, iris mata dan tanda tangan) yang tersimpan dalam fisik KTP Elektronik (KTP Elektronik). (Febriharini, 2016). Dengan teknologi ini, upaya mengubah data seperti nama, alamat, tempat tanggal lahir dan lainnya tidak akan berhasil. Satu orang hanya bisa mendaftar sekali dan hanya mendapat satu KTP. Pihak-pihak yang terlibat dalam pembuatan e-KTP antara lain adalah petugas Kelurahan serta warga (Pembuat e-KTP). Disebut elektronik, karena e-KTP yang dimiliki oleh sebagian besar Warga Negara Indonesia dilengkapi fitur utama yakin Biometrik dan Chip. Biometrik secara sederhana adalah identifikasi individu berdasarkan ciri-ciri yang melekat padanya. Ciri bisa berupa ciri fisiologis seperti sidik jari 
dan mata ataupun ciri perilaku seperti suara. Dalam e-KTP, ciri individu yang digunakan dalam biometrik adalah 10 sidik jari, iris pada dua mata dan foto wajah. Ciri tersebut secara otomatis akan disimpan ke pusat data di Kementerian Dalam Negeri saat pemilik mengurus e-KTP. Teknologi biometrik dalam e-KTP punya dua fungsi. Pertama, untuk memastikan ketunggalan identitas penduduk. Konsekuensinya, dengan teknologi ini, penduduk tidak bisa memiliki dua e-KTP baik dengan biodata sama ataupun berbeda. Fungsi kedua biometrik adalah proses verifikasi. Proses ini memastikan pemegang kartu adalah benar-benar pemiliknya. Dalam proses ini, hanya data sidik jari yang dibaca dengan bantuan perangkat pembaca e-KTP. Cip dalam e-KTP berfungsi menyimpan data biodata pemilik, tanda tangan, pas foto, dan dua data sidik jari. Default sidik jari yang dipakai adalah telunjuk tangan kanan serta telunjuk tangan kiri. (Prihadi, 2017)

Hasil analisis sistem untuk penelitian ini adalah dapat dikembangkan menjadi sistem jaringan operasi pembuatan e-KTP yang handal,cepat dan akurat sehingga penduduk di Kecamatan Kartasura Kabupaten Sukoharjo pada khususnya menjadi puas atas kinerja sistem e-KTP ini.

Hambatan-hambatan yang mungkin ada dalam proses pembuatan e-KTP ini, pengaruh presepsi akurasi sistem pembuatan e-KTP terhadap kepuasan penduduk dan pengaruh presepsi tepat waktu pembuatan e-KTP terhadap kepuasan penduduk.

Tujuan dari penelitian ini adalah untuk mengetahui presepsi akurasi dan presepsi tepat waktu sistem pembuatan e-KTP terhadap kepuasan penduduk apakah sistem tersebut dapat dipercaya pengguna untuk memperoleh data yang diperlukan.

\section{TINJAUAN PUSTAKA}

Dalam penelitian William J. Doll (1991) untuk menentukan end user computing, mereka membedakan antara primer dan sekunder peran pengguna. Pengguna utama membuat keputusan berdasarkan output sistem. Pengguna sekunder bertanggung jawab untuk berinteraksi dengan perangkat lunak aplikasi untuk memasukkan informasi atau mempersiapkan laporan output, tetapi tidak menggunakan output tidak langsung dalam pekerjaan nya. Dalam komputasi pengguna akhir, dua peran digabungkan: orang yang hubungan listrik sistem keluaran juga mengembangkan itu. Sebaliknya, fasilitas pengguna akhir CODASYL commiee (Lefkovits, 1979) memberikan definisi defisiensi yang lebih luas dari end-user computing meliputi: "-individu rect" pengguna akhir yang menggunakan komputer melalui orang lain; "Intermediate" pengguna akhir yang alamiah lainnya persyaratan informasi bisnis untuk laporan mereka akhirnya menerima; dan "langsung" pengguna akhir yang benar-benar menggunakan terminal. Namun, untuk sebagian besar, penulis di daerah ini seperti Martin (1982), Mclean (1979), dan Rockart dan Nery Flan(1983) membatasi definisi mereka pengguna akhir untuk individu yang berinteraksi langsung dengan komputer. (Doll \& Torkzadeh, 1991)

Penelitian yang dilakukan Mohd Rushdan Bin Yasoa' ini adalah untuk mengukur tingkat kepuasan pengguna akhir sistem akuntansi terkomputerisasi di universitas dan perguruan tinggi universitas publik. Ulasan ini juga menilai hubungan signifikan antara faktor-faktor kepuasan pengguna akhir komputer (isi informasi, ketepatan informasi, format, kegunaan, ketepatan waktu, kecepatan sistem dan keandalan sistem) dengan keseluruhan kepuasan pengguna akhir dalam konteks Malaysia. Selain itu, penelitian ini juga menguji perbedaan persepsi yang signifikan terhadap kepuasan pengguna akhir secara keseluruhan oleh faktor-faktor yang lain seperti gender, latarbelakang pendidikan, jabatan, masa jabatan, dan kursus akuntansi terkomputerisasi. Akhirnya, penelitian ini memberikan hasil penelitian dari tes empiris terhadap hubungan-hubungan ini. Pengujian dilakukan menggunakan tes Korelasi Pearson, tes T dan ANOVA (analisis varians). (Mohamed, 2006). 
Menurut Doll dan Torkzadeh (1988) definisi End User Computing Satisfaction sebuah sistem informasi adalah evaluasi secara keseluruhan para pengguna sistem informasi yang berdasarkan pengalaman mereka dalam menggunakan sistem tersebut. Evaluasi menggunakan model EUCS lebih menekankan kepuasan (satisfaction) pengguna akhir terhadap aspek teknologi, dengan menilai isi, keakuratan, format, waktu, dan kemudahan penggunaan sistem. (Camilla, 2013)

Penelitian yang dilakukan Azleen Iliasa dkk (2009) untuk menentukan hubungan antara faktor End-User Computing Satisfaction (EUCS) yaitu (konten, akurasi, format, kemudahan penggunaan, ketepatan waktu, kepuasan dengan sistem kecepatan, keandalan sistem) dan kepuasan. Penelitian dilakukan dengan menggunakan kuesioner berjumlah 90 terhadap staf yang menggunakan sistem komputerisasi akuntasi. Hasil empiris penelitian ini dapat memberikan dukungan untuk model Doll dan Torkzadeh (1988), yang berkaitan dengan faktor-faktor yang berkontribusi terhadap kepuasan pengguna akhir terhadap sistem akuntansi. Selain itu, penelitian ini juga mengevaluasi hubungan yang kuat antara faktor EUCS dan kepuasan terhadap penggunaan computerised accounting system (CAS). Faktor EUCS sangat mempengaruhi kepuasan pengguna akhir pada saat menangani Sistem Perancangan dan Kawalan Belanjawan Elektronik (e-SPKB). (Ilias, 2009)

Hasil Penelitian dari Jein Rewah (2017) menunjukkan bahwa dari lima variabel independen hanya satu variabel yang berpengaruh secara signifikan terhadap Sistem Informasi (SI) e-KTP. Secara serentak juga menunjukan bahwa kelima variabel independen tidak berpengaruh terhadap SI e-KTP. Hasil ini menunjukan bahwa ada ketimpangan dalam penerapan SI e-KTP sehingga dibutuhkan penelitian yang lanjut untuk mengetahui faktor yang menyebabkan ketimpangan ini. (Rewah, Studi, Informasi, \& Klabat, 2017)

\section{METODE PENELITIAN \\ 1. Jenis Data}

\section{a. Data Primer}

Data primer merupakan sekumpulan data yang diperoleh secara langsung oleh penelitian dari responden melalui wawancara dan penyebaran kuisioner pada penduduk di Kecamatan Kartasura, Kabupaten Sukoharjo.

\section{b. Data Sekunder}

Data sekunder merupakan data yang dikumpulkan pada studi sebelumnya atau yang diterbitkan oleh instansi lainnya dan bisa diperoleh melalui arsip, buku referensi, dan internet yang dapat menunjang penelitian. Data sekunder diperoleh dari web Dukcapil (Direktorat Jendral Kependudukan dan Pencatatan Sipil) (Kumolo, 2016) serta diambil dari web resmi Kecamatan Kartasura Kabupaten Sukoharjo ("Profil Kecamatan Kartasura Kabupaten Sukoharjo,” 2016)

\section{Populasi dan Sampel}

Populasi dan sampel penelitian ini adalah sebanyak 120 penduduk dari Kecamatan Kartasura, Kabupaten Sukoharo yang terkait dengan e-KTP. Setiap anggota populasi ini menjadi data penelitian.

\section{Variabel penelitian}

Penelitian ini menggunakan 5 (tiga) indikator variabel yang telah dimodifikasi dari model penelitian EUCS sebelumnya yaitu :isi sistem informasi sebagai variabel bebas pertama (X1). Akurasi sistem informasi sebagai variabel bebas kedua (X2). Kemudahan Sebagai variabel bebas ketiga (X3). Tepat Waktu sebagai variabel bebas keempat (X4). Kepuasan penggunaan sistem informasi sebagai variabel terikat (Y).

\section{Teknik Pengambilan Data}

Terdiri dari assement, uji validitas dan uji reliabilitas 


\section{Teknik Analisis Data}

Terdiri dari pengujian Asumsi Klasik (Uji Normalitas data, Uji Multikolinearitas dan Uji Heteroskedastisitas) Pengujian Regresi Linier Berganda. Perhitungan Nilai Koefisien Determinasi dan Uji Hipotesis dengan Uji T-test dan F-test.

\section{HASIL DAN PEMBAHASAN}

\section{Deskripsi Objek Penelitian}

Responden yang menjadi objek penelitian adalah 120 penduduk di Kecamatan Kartasura Kabupaten Sukoharjo. Penyebaran kuisioner dilakukan selama 10 hari dari tanggal 4 Maret 2017 s.d 13 Maret 2017. Kuisioner ini di distribusikan dan diisi oleh 120 penduduk seeprti pada Tabel 1 dan semua kuisinoner berhasil dan layak untuk dijadikan data primer

Tabel 1. Data Penduduk

\begin{tabular}{|c|l|l|c|c|c|c|}
\hline No & Nama & Kelurahan & Jenis Kelamin & Usia & Pendidikan & Pekerjaan \\
\hline 1 & Dona W & Wirogunan & Wanita & $17-25 \mathrm{Th}$ & SMA & Mahasiswa \\
\hline 2 & Sri W & Kartasura & Wanita & $26-40 \mathrm{Th}$ & SMA & DLL \\
\hline 3 & Nur K & Kartasura & Wanita & $17-25 \mathrm{Th}$ & SMA & Mahasiswa \\
\hline 4 & Dian S & Wirogunan & Wanita & $17-25 \mathrm{Th}$ & SMA & Mahasiswa \\
\hline 5 & Muh A & Makamhaji & Pria & $17-25 \mathrm{Th}$ & SMA & Mahasiswa \\
\hline 6 & Suswantini & Ngadirejo & Wanita & $26-40 \mathrm{Th}$ & SMA & Swasta \\
\hline 7 & Safitri & Ngabeyan & Wanita & $17-25 \mathrm{Th}$ & SMA & Mahasiswa \\
\hline 8 & Siti N & Ngabeyan & Wanita & $26-40 \mathrm{Th}$ & SMA & DLL \\
\hline 9 & Nurul & Ngabeyan & Wanita & $26-40 \mathrm{Th}$ & SMA & DLL \\
\hline 10 & Daniel & Makamhaji & Pria & $17-25 \mathrm{Th}$ & SMA & Mahasiswa \\
\hline$\vdots$ & $\vdots$ & $\vdots$ & $\vdots$ & $\vdots$ & $\vdots$ \\
& & & & & \\
\hline 120 & Novia & Ngadirejo & Wanita & $17-19 \mathrm{Th}$ & SMA & Mahasiswa \\
\hline
\end{tabular}

Sumber : Data primer yang telah diolah (2017)

Data kuisioner yang diisi oleh penduduk seperti pada Tabel 2.

Tabel 2. Data Kuisioner

\begin{tabular}{|c|c|c|c|c|c|c|c|c|c|c|c|c|c|}
\hline No & Nama & X11 & X12 & X21 & $\mathrm{X} 22$ & X31 & X32 & X41 & $\mathrm{X} 42$ & Y1 & Y2 & Y3 & Y4 \\
\hline 1 & Dona W & 4 & 4 & 3 & 4 & 5 & 3 & 3 & 3 & 5 & 2 & 3 & 2 \\
\hline 2 & Sri W & 4 & 4 & 4 & 4 & 4 & 4 & 4 & 4 & 5 & 2 & 3 & 5 \\
\hline 3 & Nur K & 4 & 4 & 4 & 4 & 4 & 4 & 3 & 3 & 4 & 3 & 2 & 3 \\
\hline 4 & Dian S & 4 & 4 & 4 & 3 & 5 & 3 & 2 & 4 & 5 & 3 & 3 & 2 \\
\hline 5 & Muh A & 4 & 4 & 4 & 3 & 4 & 3 & 2 & 4 & 4 & 2 & 3 & 4 \\
\hline 6 & Suswantini & 4 & 4 & 4 & 4 & 4 & 4 & 4 & 4 & 4 & 3 & 5 & 5 \\
\hline 7 & Safitri & 3 & 4 & 3 & 4 & 5 & 3 & 2 & 3 & 3 & 2 & 3 & 2 \\
\hline 8 & Siti N & 3 & 5 & 3 & 4 & 5 & 3 & 2 & 3 & 3 & 2 & 3 & 2 \\
\hline 9 & Nurul & 4 & 4 & 3 & 4 & 5 & 3 & 2 & 4 & 4 & 3 & 3 & 5 \\
\hline 10 & Daniel & 4 & 4 & 4 & 4 & 4 & 4 & 4 & 4 & 5 & 3 & 3 & 4 \\
\hline & $\begin{array}{ccc}\vdots & \vdots & \vdots \\
\vdots & \vdots & \vdots\end{array}$ & $\begin{array}{l}\vdots \\
\vdots\end{array}$ & & & & & & & & & $\vdots$ & & $\vdots$ \\
\hline 120 & Novia & 4 & 4 & 3 & 3 & 2 & 2 & 2 & 4 & 3 & 2 & 3 & 3 \\
\hline
\end{tabular}

Sumber : Data primer yang telah diolah (2017)

Rincian jumlah responden seperti pada Tabel 3, sedang rincian jumlah kuisioner dapat dilihat pada Tabel 4. 
Tabel 3. Rincian Responden

\begin{tabular}{|c|l|r|}
\hline No & \multicolumn{1}{|c|}{ Alamat } & \multicolumn{1}{|c|}{ Jumlah } \\
\hline 1 & Ngadirejo & 47 \\
\hline 2 & Ngabeyan & 8 \\
\hline 3 & Singopuran & 5 \\
\hline 4 & Gonilan & 4 \\
\hline 5 & Kartasura & 15 \\
\hline 6 & Pabelan & 9 \\
\hline 7 & Kertonatan & 0 \\
\hline 8 & Makamhaji & 10 \\
\hline 9 & Ngemplak & 2 \\
\hline 10 & Pucangan & 6 \\
\hline 11 & Gumpang & 10 \\
\hline 12 & Wirogunan & 4 \\
\hline & Total & 120 \\
\hline
\end{tabular}

Sumber : Data primer yang telah diolah (2017)

Tabel 4. Rincian Jumlah Kuisioner

\begin{tabular}{|l|l|}
\hline Keterangan & Jumlah \\
\hline Jumlah kuisioner disebar & 120 \\
\hline Jumlah kuisioner kembali & 120 \\
\hline Kuisioner gugur & - \\
\hline Kuisioner terpakai & 120 \\
\hline Presentase kuisioner kembali & $100 \%$ \\
\hline Presentase kuisioner gugur & $100 \%$ \\
\hline
\end{tabular}

Dari rincian jumlah kuisioner seperti pada Tabel 4 diperoleh distribusi responden yang menjelaskan mengenai jumlah dan presentase data primer berdasarkan jenis kelamin dan usia responden yang dapat dilihat pada Tabel 5.

Tabel 5. Distribusi Responden

\begin{tabular}{|l|l|l|}
\hline Keterangan & Jumlah & Presentase dari Seluruh Responden \\
\hline Jumlah data primer & 120 & $100 \%$ \\
\hline Jenis kelamin: & & \\
1. Laki-laki & 43 & $36 \%$ \\
2. Perempuan & 77 & $64 \%$ \\
\hline Usia: & & \\
1. $\quad 17-25$ tahun & 46 & $47 \%$ \\
2. 26-40 tahun & 33 & $34 \%$ \\
3. > 40 tahun & 21 & $19 \%$ \\
\hline
\end{tabular}

Sumber : Data hasil kuisioner (2017)

Berdasarkan jenis kelamin menunjukan bahwa dari 120 responden terdapat 43 responden lai-laki (36\%) dan 77 responden perempuan (64\%).

\section{Deskripsi Statistik Variabel Penelitian}

Berdasarkan hasil analisis deskriptif statistic, maka berikut didalam Tabel 5 akan ditampilkan karakteristik data primer yang digunakan didalam penelitian ini meliputi: jumlah sampel $(\mathrm{N})$, rata-rata sampel (mean), nilai maksimum, nilai minimum, serta standar devisi untuk masing-masing variabel seperti pada Tabel 6. 
Tabel 6. Deskripsi Variabel Penelitian

\begin{tabular}{|l|c|c|c|c|c|}
\hline & $\mathbf{N}$ & Min & Max & Mean & Std.Deviation \\
\hline Isi (X1) & 120 & 3 & 5 & 3,87 &, 533 \\
\hline Akurasi(X2) & 120 & 4 & 10 & 6,76 & 1,432 \\
\hline Kemudahan(X3) & 120 & 4 & 10 & 7,14 & 1,589 \\
\hline Tepat Waktu (X4) & 120 & 4 & 10 & 6,61 & 1,485 \\
\hline Kepuasan(Y) & 120 & 9 & 18 & 12,41 & 2,389 \\
\hline
\end{tabular}

Sumber : Data primer yang telah diolah (2017)

Pada Tabel 6. menunjukkan jumlah data yang digunakan dalam penelitian ini sebanyak 120 data yang diteliti selama 10 hari. Berdasarkan hasil perhitungan tampak bahwa nilai variabel Isi tertinggi (maximum) sebesar 5\% dan nilai terendah (minimum) sebesar3\%. Standar deviasi sebesar 0,533\% lebih kecil dibandingkan dengan nilai mean (rata-rata) yaitu sebesar $3,87 \%$ berarti simpangan variable isi sistem informasi dapat dikatakan baik.

Nilai Akurasi tertinggi sebesar $10 \%$ dan nilaiterendah sebesar $4 \%$. Nilai standar deviasi sebesar $1,432 \%$ lebih kecil dibandingkan dengan nilai mean (rata-rata) yaitu sebesar $6,76 \%$, sehingga simpangan data pada variabel tepat waktu sistem informasi ini dapat dikatakan baik.

Nilai Kemudahan tertinggi sebesar $10 \%$ dan nilai terendah sebesar $4 \%$. Nilai standar deviasi sebesar 1,589\% lebih kecil dibandingkan dengan nilai mean (rata-rata) yaitu sebesar $7,14 \%$, sehingga simpangan data pada variabel tepat waktu sistem informasi ini dapat dikatakan baik.

Nilai Tepat Waktu tertinggi sebesar $10 \%$ dan nilai terendah sebesar $4 \%$. Nilai standar deviasi sebesar 1,485\% lebih kecil dibandingkan dengan nilai mean (rata-rata) yaitu sebesar $6,61 \%$, sehingga simpangan data pada variabel tepat waktu sistem informasi ini dapat dikatakan baik.

Nilai Kepuasan sistem informasi tertinggi sebesar 18\% dan nilai terendah sebesar 9\%. Nilai standar deviasi sebesar 2.389\% lebih kecil dibandingkan dengan nilai mean (rata-rata) yaitu sebesar $12,41 \%$, sehingga simpangan data pada variabel kepuasan sistem informasi ini dapat dikatakan baik.

\section{Uji Validitas dan Reliabilitas}

\section{a. Uji Validitas}

Uji Validitas digunakan untuk mengetahui apakah semua (lima) pernyataan (instrumen) penelitian yang diajukan untuk mengukur variabel penelitian adalah valid. Pengujian validitas dengan mengkorelasikan antara skor butir instrumen dengan skor total, untuk menghitung korelasi pada uji validitas menggunakan korelasi product moment Pearson. Dari hasil analisis didapat skor item dengan skor total. Jika nilai korelasi butir instrumen $>0,3$ maka butir instrumen dinyatakan valid dan sebaliknya jika bila korelasi butir instrumen $<0,3$ maka dapat disimpulkan butir instrumen tersebut tidak berkorelasi dengan skor total dan dinyatakan tidak valid. Keseluruhan hasil uji validitas setiap variabel menggunakan alat bantu program SPSS Statistics 15.

Berdasarkan Tabel 7 maka dapat disimpulkan bahwa instrument isi dinyatakan valid untuk digunakan dalam proses pengelolaan analisa data karena hasil korelasi tiap poin pernyataan menghasilkan nilai korelasi butir instrumen $>0,03$.

Tabel 7. Ringkasan Hasil Uji Validitas Isi

\begin{tabular}{|c|c|c|c|}
\hline $\begin{array}{c}\text { Poin. } \\
\text { Pertanyaan }\end{array}$ & $\begin{array}{c}\text { Korelasi Skor Poin Pertanyaan } \\
\text { terhadap Skor Total }\end{array}$ & r Tabel & Ket \\
\hline X11 & 0.861 & 0,18 & Valid \\
\hline X12 & 0.899 & 0,18 & Valid \\
\hline
\end{tabular}

Sumber : Data primer yang telah diolah (2017) 
Berdasarkan Tabel 8 maka dapat disimpulkan bahwa instrument akurasi dinyatakan valid untuk digunakan dalam proses pengelolaan analisa data karena hasil korelasi tiap poin pernyataan menghasilkan nilai korelasi butir instrumen $>0,03$.

Tabel 8. Ringkasan Hasil Uji Validitas Variabel Akurasi

\begin{tabular}{|l|c|c|c|}
\hline $\begin{array}{c}\text { Poin. } \\
\text { Pertanyaan }\end{array}$ & $\begin{array}{c}\text { Korelasi Skor Poin Pertanyaan } \\
\text { terhadap Skor Total }\end{array}$ & r Tabel & Ket \\
\hline X21 & 0.902 & 0,18 & Valid \\
\hline X22 & 0.871 & 0,18 & Valid \\
\hline
\end{tabular}

Sumber : Data primer yang telah diolah (2017)

Berdasarkan Tabel 9 maka dapat disimpulkan bahwa instrument kemudahan dinyatakan valid untuk digunakan dalam proses pengelolaan analisa data karena hasil korelasi tiap poin pernyataan menghasilkan nilai korelasi butir instrumen > 0,03 .

Tabel 9. Ringkasan Hasil Uji Validitas Variabel Kemudahan

\begin{tabular}{|l|c|c|c|}
\hline $\begin{array}{c}\text { Poin. } \\
\text { Pertanyaan }\end{array}$ & $\begin{array}{c}\text { Korelasi Skor Poin Pertanyaan } \\
\text { terhadap Skor Total }\end{array}$ & r Tabel & Ket \\
\hline X31 & 0.887 & 0,18 & Valid \\
\hline X32 & 0.874 & 0,18 & Valid \\
\hline
\end{tabular}

Sumber : Data primer yang telah diolah (2017)

Berdasarkan Tabel 10 maka dapat disimpulkan bahwa instrument Tepat Waktu dinyatakan valid untuk digunakan dalam proses pengelolaan analisa data karena hasil korelasi tiap poin pernyataan menghasilkan nilai korelasi butir instrumen > 0,03 .

Tabel 10. Ringkasan Hasil Uji Validitas Variabel Tepat Waktu

\begin{tabular}{|l|c|c|c|}
\hline $\begin{array}{c}\text { Poin } \\
\text { Pertanyaan }\end{array}$ & $\begin{array}{c}\text { Korelasi Skor Poin Pertanyaan } \\
\text { terhadap Skor Total }\end{array}$ & r Tabel & Ket \\
\hline X41 & 0.852 & 0,18 & Valid \\
\hline X42 & 0.841 & 0,18 & Valid \\
\hline
\end{tabular}

Sumber : Data primer yang telah diolah (2017)

Berdasarkan Tabel 11 maka dapat disimpulkan bahwa instrument Kepuasan dinyatakan valid untuk digunakan dalam proses pengelolaan analisa data karena semua hasil korelasi tiap poin pernyataan menghasilkan nilai korelasi butir instrumen $>0,03$.

Tabel 11. Ringkasan Hasil Uji Validitas Kepuasan

\begin{tabular}{|c|c|c|c|}
\hline $\begin{array}{c}\text { Poin } \\
\text { Pertanyaan }\end{array}$ & $\begin{array}{c}\text { Korelasi Skor Poin Pertanyaan } \\
\text { terhadap Skor Total }\end{array}$ & R Tabel & Ket \\
\hline Y1 & 0.723 & 0,18 & Valid \\
\hline Y2 & 0.658 & 0,18 & Valid \\
\hline Y3 & 0.568 & 0,18 & Valid \\
\hline Y4 & 0.765 & 0,18 & Valid \\
\hline
\end{tabular}

Sumber : Data primer yang telah diolah (2017)

\section{b. Uji Reabilitas}

Selanjutnya poin-poin pernyataan kuisioner yang valid diuji tingkat reliabilitasnya dengan menggunakan teknik alpha cronbach. Butir instrumen dinyatakan reliabel (andal) bila memiliki nilai alpha cronbach $>0,6$. Tabel nilai alpha pada butir instrumen atau poin pernyataan kuisioner pada variable isi sistem informasi (X1), 
akurasi sistem informasi (X2), kemudahan sistem informasi (X3), tepat waktu sistem informasi(X4) dan kepuasan sistem informasi (Y) bernilai diatas 0,6 atau > 0,6 maka dapat dinyatakan reliable. Ringkasan hasil uji realibilitas terhadap keseluruhan variabel penelitian dapat dilihat pada Tabel 12.

Tabel 12. Ringkasan Hasil Uji Reliabilitas Keseluruhan Variabel Penelitian

\begin{tabular}{|l|c|c|c|c|}
\hline \multicolumn{1}{|c|}{ Variabel } & Nilai Alpha & R Tabel & $\begin{array}{c}\text { Reliabilitas } \\
\text { diterima }\end{array}$ & Ket \\
\hline X1 & 0.706 & 0,18 & 0.60 & Reliabel \\
\hline X2 & 0,725 & 0,18 & 0.60 & Reliabel \\
\hline X3 & 0.710 & 0,18 & 0.60 & Reliabel \\
\hline X4 & 0,604 & 0,18 & 0.60 & Reliabel \\
\hline Y & 0,614 & 0,18 & 0.60 & Reliabel \\
\hline
\end{tabular}

Sumber : Data primer yang telah diolah (2017)

\section{Uji Asumsi Klasik}

Uji asumsi klasik, dimana sebelum melakukan pengujian regresi berganda, terlebih dahulu menguji variabel yang ada dengan pengujian asumsi klasik, diantaranya yaitu uji normalitas dan uji multikolinearitas

\section{a. Uji Normalitas}

Uji normalitas bertujuan untuk menguji apakah dalam model regresi variabel dependen, variabel independen atau keduanya memiliki distribusi normal ataukah tidak mempunyai distribusi normal. Salah satu metode untuk mengetahui normalitas adalah metode analisis statistik yaitu dengan menggunakan Uji Kolmogorov-Smirnov. Data yang berdistribusi normal ditunjukkan dengan nilai signifikansi di atas 0,05. Hasil pengujian terhadap 100 data terlihat dalam Tabel 13 berikut :

Tabel 13. Uji Statistik Non-Parametrik

One-Sample Kolmogorov-Smirnov Test

\begin{tabular}{|ll|r|}
\hline & & $\begin{array}{c}\text { Unstandardized } \\
\text { Residual }\end{array}$ \\
\hline $\mathrm{N}$ & Mean & 120 \\
Normal & Std. & .0000000 \\
Parameters(a,b) & Deviation & .38443868 \\
Most Extreme & Absolute & .054 \\
Differences & Positive & .054 \\
& Negative & -.041 \\
Kolmogorov-Smirnov Z & .590 \\
Asymp. Sig. (2-tailed) & .877 \\
\hline \multicolumn{2}{|c|}{ Sumber : Data primer yang telah diolah (2017) }
\end{tabular}

Dari nilai output dapat diketahui bahwa nilai Asymp. Sig (2-tailed) sebesar 0.877. Hal ini berarti bahwa data telah terdistribusi normal karena nilai Asymp. Sig. di atas 0,05 .

\section{b. Uji Multikolinearitas}

Uji multikolinearitas bertujuan untuk menguji adanya korelasi antar variabel bebas (independen). Suatu model persamaan regresi harus bebas dari gejala multikolinearitas yang berarti tidak terdapat korelasi yang kuat antara variabel independen yang satu dengan variabel independen lainnya dalam suatu model persamaan regresi. Pengujian asumsi multikolinearitas dilakukan dengan melihat 
nilai variance inflation factor (VIF) dan nilai tolerance value-nya. Suatu model persamaan regresi dikatakan bebas dari gejala multikolinearitas, apabila nilai dari variance inflation factor (VIF) di bawah 10 dan nilai tolerance value-nya di atas 0,10 . Hasil dari uji VIF pada Tabel 14 menunjukkan bahwa kedua variabel independen tidak terjadi multikolinearitas karena nilai VIF $<10$ dan TOL $>0,1$ sehingga dapat disimpulkan bahwa tidak ada multikolinearitas dan dapat digunakan untuk memprediksi tingkat kepuasan e-KTP.

Tabel 14. Uji Variance Inflation Factor (VIF)

Coefficients $^{\mathrm{a}}$

\begin{tabular}{|c|c|c|c|c|c|c|c|c|}
\hline \multirow{2}{*}{\multicolumn{2}{|c|}{ Model }} & \multicolumn{2}{|c|}{$\begin{array}{l}\text { Unstandardized } \\
\text { Coeff icients }\end{array}$} & \multirow{2}{*}{$\begin{array}{c}\text { Standardized } \\
\text { Coefficients } \\
\text { Beta }\end{array}$} & \multirow[b]{2}{*}{$t$} & \multirow[b]{2}{*}{ Sig. } & \multicolumn{2}{|c|}{ Collinearity Statistics } \\
\hline & & $\mathrm{B}$ & Std. Error & & & & Tolerance & VIF \\
\hline \multirow[t]{3}{*}{1} & (Constant) & 14.021 & 2.905 & & 4.826 & .000 & & \\
\hline & Akurasi & -.088 & .230 & -.039 & -.381 & .704 & .952 & 1.050 \\
\hline & Tepat_Waktu & .150 & .111 & .139 & 1.352 & .179 & .952 & 1.050 \\
\hline
\end{tabular}

a. Dependent Variable: Kepuasan

Sumber : Data primer yang telah diolah (2017)

\section{c. Uji Heteroskedastisitas}

Uji heteroskedastisitas digunakan untuk mengetahui ada atau tidaknya ketidaksamaan varian dari residual pada model regresi. Prasyarat yang harus terpenuhi dalam model regresi adalah tidak adanya masalah heteroskedastisitas. Untuk menentukan heteroskedastisitas dapat menggunakan grafik scatterplot atau dengan metode Glejser, pada grafik scatterplot titik-titik harus menyebar secara acak, tersebar baik di atas maupun di bawah angka 0 pada sumbu $Y$, bila kondisi ini terpenuhi maka tidak terjadi heteroskedastisitas dan model regresi layak digunakan. Hasil uji heteroskedastisitas dengan menggunakan uji Glejser ditunjukkan dengan Tabel 20. Pada Tabel 15 terlihat bahwa nilai sig keempat variabel $>0.05$. Hal ini dapat disimpulkan bahwa tidak terjadi masalah heterokedastisitas pada model regresi yang digunakan.

Tabel 15. Uji Glejser

Coefficients(a)

\begin{tabular}{|ll|r|r|r|r|r|}
\hline Model & \multicolumn{2}{|c|}{$\begin{array}{c}\text { Unstandardized } \\
\text { Coefficients }\end{array}$} & $\begin{array}{c}\text { Standardized } \\
\text { Coefficients }\end{array}$ & \multicolumn{1}{c|}{ t } & \multicolumn{1}{c|}{ Sig. } \\
\cline { 3 - 7 } & \multicolumn{1}{|c|}{ B } & \multicolumn{1}{|c|}{ Std. Error } & \multicolumn{1}{c|}{ Beta } & \multicolumn{1}{c|}{ B } & \multicolumn{1}{c|}{ Std. Error } \\
\hline 1 & (Constant) &, 179 &, 180 & &, 994 &, 323 \\
& X1 &,- 050 &, 046 &,- 109 & $-1,068$ &, 288 \\
& X2 &, 020 &, 034 &, 060 &, 587 &, 558 \\
&, 010 &, 031 &, 032 &, 317 &, 752 \\
& X3 &, 062 &, 035 &, 191 & 1,806 &, 074 \\
\hline
\end{tabular}

Sumber : Data primer yang telah diolah (2017)

\section{Reggresi Linier Berganda}

Analisis regresi linier berganda adalah hubungan secara linear antara dua atau lebih variabel independen dengan variabel dependen. Analisis ini untuk memprediksi nilai dari variabel dependen apabila nilai variabel independen mengalami kenaikan atau penurunan dan untuk mengetahui arah hubungan antara variabel independen dengan variabel dependen, apakah berhubungan positif atau 
negatif. Dalam penelitian ini menggunakan bantuan komputer program SPSS 15, hasilnya dapat dilihat pada Tabel 15.

Tabel 15. Koefisien Regresi Linier Berganda

\begin{tabular}{|r|l|r|r|r|}
\hline \multirow{2}{*}{ Model } & \multicolumn{2}{|c|}{ Unstandardized Coefficients } & $\begin{array}{c}\text { Standardized } \\
\text { Coefficients }\end{array}$ \\
\cline { 3 - 5 } & \multicolumn{1}{|c|}{ B } & Std. Error & \multicolumn{1}{c|}{ Beta } \\
\hline 1 & (Constant) & .009 & .292 & -0.039 \\
\hline \multirow{2}{*}{} & X1 & .266 & .075 & 0.139 \\
\cline { 2 - 5 } & X2 & -.004 & .056 & .341 \\
\cline { 2 - 5 } & X3 & .256 & .050 & .438 \\
\cline { 2 - 5 } & X4 & .352 & .056 & \\
\hline
\end{tabular}

Sumber : Data primer yang telah diolah (2017)

Dari Tabel 21 diperoleh persamaan regresi sebagai berikut:

$$
\begin{aligned}
& \mathrm{X}_{1}=\text { Isi sistem informasi } \\
& \mathrm{X}_{2}=\text { Akurasi sistem informasi } \\
& \mathrm{X}_{3}=\text { Kemudahan sistem informasi } \\
& \mathrm{X}_{4}=\text { Tepat waktu sistem informasi } \\
& \mathrm{Y}=\text { Kepuasan sistem informasi } \\
& \mathrm{Y}=0.009+0.266 \mathrm{X}_{1}+-0.004 \mathrm{X}_{2}+0.256 \mathrm{X}_{3}+0.352 \mathrm{X}_{4}
\end{aligned}
$$

Berdasarkan persamaan regresi tersebut maka :

- Nilai konstanta menyatakan bahwa jika variabel independen bernilai nol maka nilai Y adalah sebesar 0.009 atau apabila tidak ada pengaruh variabel yang terdiri isi dari sistem informasi, akurasi sistem informasi, kemudahan sistem informasi dan ketepat waktuan sistem informasi atau jika $\mathrm{X}_{1}, \mathrm{X}_{2}, \mathrm{X}_{1}, \mathrm{X}_{2}=0$, maka nilai variabel dependen yaitu kondisi kepuasan sistem informasi(Y) adalah sebesar 0.009 .

- Koefisien beta( $\beta) \mathrm{X}_{1}$ bertanda positif sebesar 0.266. Hal ini menunjukkan jika isi sistem informasi mengalami kenaikan sebesar 1 maka akan menimbulkan kenaikan kepuasan sistem informasi (Y) sebesar 0.009 dengan asumsi variabel lain diabaikan dan konstan. Dengan demikian dapat diinterpretasikan bahwa isi sisteminformasi $\left(\mathrm{X}_{1}\right)$ berpengaruh positif terhadap kepuasan sistem informasi $(\mathrm{Y})$, artinya semakin tinggi kenaikan sistem informasi $\left(\mathrm{X}_{1}\right)$ maka akan semakin besar kepuasan sistem informasi (Y) yang diperoleh.

- Koefisien beta $(\beta)$ akurasi sistem informasi $\left(\mathrm{X}_{2}\right)$ bertanda negatif sebesar -0.004 . Hal ini menunjukkan jika akurasi sistem informasi $\left(\mathrm{X}_{2}\right)$ mengalami penurunan sebesar 1 maka akan menimbulkan penurunan kepuasan sistem informasi (Y) sebesar 0.009 dengan asumsi variabel lain diabaikan dan konstan. Dengan demikian dapat diinterpretasikan bahwa akurasi sistem informasi ( $\left.\mathrm{X}_{2}\right)$ berpengaruh negatif terhadap kepuasan sistem informasi (Y), artinya semakin tinggi penurunan akurasi sistem informasi $\left(\mathrm{X}_{2}\right)$ maka akan semakin kecil kepuasan sistem informasi (Y) yang diperoleh.

- Koefisien beta $(\beta)$ kemudahan sistem informasi $\left(\mathrm{X}_{3}\right)$ bertanda positif sebesar 0.256. Hal ini menunjukkan jika kemudahan sistem informasi $\left(\mathrm{X}_{3}\right)$ mengalami kenaikansebesar 1 maka akan menimbulkan kenaikan kepuasan sistem informasi (Y) sebesar 0.009 dengan asumsi variabel lain diabaikan dan konstan. Dengan demikian dapat diinterpretasikan bahwa kemudahan sistem informasi $\left(\mathrm{X}_{3}\right)$ 
berpengaruh positif terhadap kepuasan sisteminformasi (Y), artinya semakin tinggi kenaikan kemudahan sistem informasi $\left(\mathrm{X}_{3}\right)$ maka akan semakin besar kepuasan sistem informasi (Y) yang diperoleh.

- Koefisien beta $(\beta)$ tepat waktu sistem informasi $\left(\mathrm{X}_{4}\right)$ bertanda positif sebesar 0.352. Hal ini menunjukkan jika tepat waktu sistem informasi $\left(\mathrm{X}_{4}\right)$ mengalami kenaikansebesar 1 maka akan menimbulkan kenaikan kepuasan sistem informasi (Y) sebesar 0.009 dengan asumsi variabel lain diabaikan dan konstan. Dengan demikian dapat diinterpretasikan bahwa Tepat waktu sisteminformasi $\left(\mathrm{X}_{4}\right)$ berpengaruh positif terhadap kepuasan sisteminformasi (Y), artinya semakin tinggi kenaikan Tepat Waktu sistem informasi $\left(\mathrm{X}_{3}\right)$ maka akan semakin besar kepuasan sistem informasi (Y) yang diperoleh.

Dari hasil analisis dapat diketahui bahwa variabel bebas yang paling berpengaruh adalah variabel tepat waktu sistem informasi $\left(\mathrm{X}_{4}\right)$ dengan koefisien beta $(\beta)$ sebesar 0,352 . Kemudian diikuti oleh dengan variabel isi sistem informasi $\left(\mathrm{X}_{1}\right)$ koefisien beta $(\beta)$ sebesar 0.266 , selanjutnya variabel kemudahan sistem informasi $\left(\mathrm{X}_{3}\right)$ koefisien beta $(\beta)$ sebesar 0,256 dan terahkier adalah variabel Akurasi dengan koefisien beta $(\beta)$ sebesar $-0,004$.

\section{Koefisien Determinasi $\left(\mathbf{R}^{2}\right)$}

Koefisien determinasi $\left(\mathrm{R}^{2}\right)$ pada penelitian ini dilakukan untuk mengukur seberapa jauh kemampuan model menerangkan variabel dependen. Adapun nilai adjusted $\mathrm{R}^{2}$ dari hasil perhitungan menggunakan SPSS for windows versi 15 dapat dilihat pada Tabel 16.

Tabel 16. Koefisien Determinasi $\left(\mathrm{R}^{2}\right)$

\begin{tabular}{|l|r|r|r|r|}
\hline \multicolumn{1}{|c|}{ Model } & R & R Square & \multicolumn{1}{c|}{$\begin{array}{c}\text { Adjusted R } \\
\text { Square }\end{array}$} & $\begin{array}{c}\text { Std. Error of the } \\
\text { Estimate }\end{array}$ \\
\hline 1 & $.756(\mathrm{a})$ & .586 & .571 & .39107 \\
\hline
\end{tabular}

Sumber : Data primer yang telah diolah (2017)

Berdasarkan Tabel 16 dapat diketahui bahwa pengaruh keempat variabel bebas (independen) terhadap variabel Kepuasan Penduduk terhadap Sistem Informasi dinyatakan dengan nilai koefisien determinasi $\left(\mathrm{R}^{2}\right)$ yaitu sebesar 0.571 atau $57,1 \%$. Hal ini berarti $57,1 \%$ variasi Kepuasan Penduduk terhadap Sistem Informasi yang bisa dijelaskan oleh variasi dari keempat variabel indepenen yaitu Isi, Akurasi, Kemudahan dan Tepat Waktu Sistem Informasi. Sedangkan sisanya sebesar 100\% $57,1 \%=42,9 \%$ dijelaskan oleh variabel lain di luar model.

\section{Uji Hipotesis dengan T-Test dan F-Test}

\section{a. Uji T-Test}

Berdasarkan Tabel 17 Koefisien Regresi Linier Berganda, diperoleh $t_{\text {hitung }}$ untuk Isi Sistem Informasi adalah 3.528, $\mathrm{t}_{\text {hitung }}$ untuk Akurasi Sistem Informasi sebesar -069, Kemudahan Sistem Informasi sebesar 5.105, dan Tepat Waktu Sistem Informasi sebesar 6.288, sedangkan $t_{\text {tabel }}$ pada taraf signifikan $5 \%$ sebesar 1.98081 . 
Tabel. 17. Koefisian Regresi Linier Berganda

\section{Coefficients(a)}

\begin{tabular}{|ll|r|r|r|r|r|}
\hline Model & & \multicolumn{2}{|c|}{$\begin{array}{c}\text { Unstandardized } \\
\text { Coefficients }\end{array}$} & $\begin{array}{c}\text { Standardized } \\
\text { Coefficients }\end{array}$ & \multirow{2}{*}{ t } & \multirow{2}{*}{ Sig. } \\
\cline { 1 - 3 } & & \multicolumn{1}{|c|}{ B } & \multicolumn{1}{|c|}{ Std. Error } & \multicolumn{1}{c|}{ Beta } & & \\
\hline 1 & (Constant) &, 009 &, 292 & &, 031 &, 975 \\
& x1 &, 266 &, 075 &, 237 & 3,528 &, 001 \\
& x2 &,- 004 &, 056 &,- 005 &,- 069 &, 945 \\
& x3 &, 256 &, 050 &, 341 & 5,105 &, 000 \\
& x4 &, 352 &, 056 &, 438 & 6,288 &, 000 \\
\hline
\end{tabular}

\section{b. Uji F-Test}

Untuk membuktikan kebenaran hipotesis, peneliti menggunakan uji $\mathrm{F}$ yaitu uji kelayakan model untuk mengetahui pengaruh variabel-variabel independen (Isi, Akurasi, Kemudahan dan Tepat Waktu) secara simultan (bersama-sama) terhadap variabel dependen Kepuasan dengan cara membandingkan $F_{\text {hitung }}$ dengan $F_{\text {tabel }}$, sebagaimana ditunjukkan dalam Tabel 18 sebagai berikut :

Tabel 18. Koefisien Uji F

ANOVA ${ }^{b}$

\begin{tabular}{|l|r|r|r|r|r|}
\hline \multicolumn{1}{|c|}{ Model } & \multicolumn{1}{c|}{$\begin{array}{c}\text { Sum of } \\
\text { Squares }\end{array}$} & Df & Mean Square & F & \multicolumn{1}{c|}{ Sig. } \\
\hline 1 Regression & 24.850 & 4 & 6.212 & 40.622 & $.000^{\mathrm{a}}$ \\
Residual & 17.587 & 115 & .153 & & \\
Total & 42.437 & 119 & & & \\
\hline
\end{tabular}

Sumber : Data primer yang telah diolah (2017)

Hasil analisis regresi dapat diketahui bahwa secara bersama-sama (simultan) variabel independen memiliki pengaruh yang signifikan terhadap variabel dependen. Hal ini dapat dibuktikan dari nilai $F_{\text {hitung }}$ sebesar 40.622 sedangkan $\mathrm{F}_{\text {tabel }}$ pada taraf signifikan $5 \%$ sebesar 3.08 sehingga dari hasil penghitungan tampak bahwa $F_{\text {hitung }}$ lebih besar dari $F_{\text {tabel }}(40.622>3.08)$. Dengan demikian, maka model regresi dapat digunakan untuk memprediksi Kepuasan Penduduk Sistem Informasi atau dapat dikatakan bahwa Isi, Akurasi, Kemudahan dan Tepat Waktu Sistem Informasi secara bersama-sama (simultan) berpengaruh terhadap Kepuasan Sistem Informasi.

\section{Analisa Hasil Penelitian}

Berdasarkan hasil perhitungan yang telah dilakukan maka dapat disimpulkan bahwa hipotesis atas penelitian ini :

1. Hipotesis 1 yang menyatakan bahwa Isi berpengaruh terhadap kepuasan Aplikasi Sistem Pembuatan e-KTP diterima karena hasil perhitungan uji t nilai t hitung Isi 3,528 lebih besar dari t tabel 1.98081 sehingga Isi berpengaruh secara signifikan terhadap kepuasan Aplikasi Sistem Pembuatan e-KTP

2. Hipotesis 2 yang menyatakan bahwa Akurasi tidak berpengaruh terhadap Kepuasan Aplikasi Sistem Pembuatan e-KTP ditolak karena hasil perhitungan uji 
t nilai t hitung Akurasi -.069 lebih besar dari t tabel 1.98081 sehingga Akurasi berpengaruh secara signifikan terhadap Kepuasan Sistem Pembuatan e-KTP.

3. Hipotesis 3 yang menyatakan bahwa Kemudahan berpengaruh terhadap Kepuasan Aplikasi Sistem Pembuatan e-KTP diterima karena hasil perhitungan uji t nilai t hitung Kemudahan 5.105 lebih kecil dari t tabel 1.98081 sehingga Kemudahan berpengaruh secara signifikan terhadap Kepuasan Aplikasi Sistem Pembuatan eKTP.

4. Hipotesis 4 yang menyatakan bahwa Tepat Waktu berpengaruh terhadap Kepuasan Aplikasi Sistem Pembuatan e-KTP diterima karena hasil perhitungan uji t nilai t hitung tepat waktu 6.288 lebih besar dari t tabel 1.98081sehingga tepat waktu berpengaruh secara signifikan terhadap kepuasan Aplikasi Sistem Pembuatan e-KTP.

Dari hasil penelitian ini sesuai dengan hasil penelitian yang diperoleh Dea Ratna Dewi Camilla (2012), dimana Dea Ratna Dewi Camilla menggunakan variabel Content, Accuracy, Format, Ease of Use, dan pengaruh secara simultan menunjukan bahwa Content (X1) dan Easeof Use (X4) berpengaruh secara simultanterhadap kinerja individu, hal ini dikarenakan pada uji simultan nilai Sig $\leq 0,05$. Besarnya pengaruh dapat dilihat dari besaran $R$ Square yang menunjukan nilai sebesar 0,201 atau sebesar $20,1 \%$, sedangkan sisanya $79,9 \%$ dijelaskan oleh faktor lain diluar model ini.

\section{PENUTUP}

\subsection{Kesimpulan}

Dalam penelitian yang dilakukan menghasilkan beberapa kesimpulan. Adapun kesimpulan yang didapat adalah sebagai berikut:

1. Berdasarkan nilai R Square sebesar 0,586. Hal ini berarti 58,6\% variasi Kepuasan Pengguna terhadap e-KTP bisa dijelaskan oleh variasi dari variabel independen yaitu Isi, Akurasi, Kemudahan, dan Tepat waktu. Sedangkan sisanya sebesar 42,9\% dipengaruhi oleh sebab-sebab lain di luar model.

2. Variabel Isi Sistem Informasi (X1) secara persial atau masing-masing berpengaruh terhadap Kepuasan Sistem Informasi (Y).

3. Variabel Akurasi Sistem Informasi (X2) secara persial atau masing-masing tidak berpengaruh terhadap Kepuasan Sistem Informasi (Y).

4. Variabel Kemudahan Sistem Informasi (X3) secara persial atau masing-masing berpengaruh terhadap Kepuasan Sistem Informasi (Y).

5. Variabel Tepat Waktu Sistem Informasi (X4) secara persial atau masing-masing berpengaruh terhadap Kepuasan Sistem Informasi (Y).

6. Variabel Isi Sistem Informasi (X1), Akurasi Sistem Informasi (X2), Kemudahan Sistem Informasi (X3) dan Tepat Waktu Sistem Informasi (X4) secara bersamasama (simultan) berpengaruh terhadap Kepuasan Sistem Informasi (Y).

\subsection{Saran}

Berdasarkan Analisis e-KTP Di Kecamatan Kartasura Kabupaten Sukoharjo dengan menggunakan metode EUCS, maka untuk peneliti selanjutnya disarankan agar sistem e-KTP ini dapat dikembangkan menjadi lebih baik, yaitu:

1. Untuk penelitian yang akan datang diharapkan untuk mengembangkan variabel yang diteliti dan memperluas data dari populasi dan sampel Kecamatan tidak hanya variabel Akurasi, Ketepatan Waktu dan Kepuasan penduduk tetapi mengambil variabel lebih banyak lagi, sehingga diperoleh daya generasi hasil 
penelitian yang lebih besar. Selain itu, periode pengamatan perlu diperpanjang untuk dapat memberikan gambaran yang lebih akurat.

2. Penambahan tools-tools yang ada pada sistem pembuatan e-KTP untuk mempermudah dan menunjang Sistem informasi yang sudah ada secara cepat.

\section{DAFTAR PUSTAKA}

Camilla, D. R. D. (2013). Pengaruh Tingkat Kepuasan Pengguna Sistem Dengan Metode End User Computing Satisfaction Terhadap Kinerja Individu Pengguna Sistem(Studi Kasus Pada Pengguna Sistem Aplikasi TiCARES PT Telekomunikasi Indonesia, Tbk).

Doll, W. J., \& Torkzadeh, G. (1991). The measurement of end-user computing satisfaction: theoretical and methodological issues. MIS Quarterly Society for Information Management and The Management Information Systems Research Center Minneapolis, MN, USA, 15(Issue 1), 5-10. https://doi.org/10.2307/249429

Febriharini, M. P. (2016). Pelaksanaan Program e KTP Dalam Rangka Tertib Administrasi Kependudukan. Serat Acitya -Jurnal Ilmiah UNTAG Semarang, Vol. 5(No. 2), 17-30.

Ilias, A. (2009). End-User Computing Satisfaction ( EUCS ) in Computerised Accounting System ( CAS ): Which the Critical Factors? A Case in Malaysia, 2(1), 18-24.

Kumolo, T. (2016). Surat Edaran Mendagri Nomor 470/296/SJ Tentang KTP-el Berlaku Seumur Hidup (Untuk Gubernur, Bupati/Walikota). Retrieved June 14, 2016, from http://www.dukcapil.kemendagri.go.id/peraturan/detail/75/surat-edaran-mendagrinomor-470296SJ-tentang-ktp-el-berlaku-seumur-hidup--untuk-gubernurbupatiwalikota.

Mohamed, A. (2006). The Study of End-User Computing Satisfaction ( EUCS ) on Computerised Accounting System ( CAS ) Among Peninsular Malaysia Public Universities: A Survey in Bursar' s Office. Labuan E-Journal of Muamalat and Society 2(October 2015), 594-608. Retrieved from http://wwwkal.ums.edu.my/LJMS/Volume_1_2007/LJMS_vol1_2007_1-13[1].pdf

Prihadi, S. D. (2017). Mengenal Fungsi Biometrik \& Chip di e-KTP. Retrieved December 1, 2017, from https://www.cnnindonesia.com/teknologi/20170309140234-185198990/mengenal-fungsi-biometrik-chip-di-e-ktp

Profil Kecamatan Kartasura Kabupaten Sukoharjo. (2016). Retrieved June 14, 2016, from http://www.kartasura.sukoharjokab.go.id/

Rewah, J., Studi, P., Informasi, S., \& Klabat, U. (2017). Analisis Efektifitas Sistem Informasi E-Ktp Di Dinas Kependudukan Dan Pencatatan Sipil ( Dispendcapil ) Minahasa Utara Effectivity Analysis of e-Ktp Information System at Dinas Kependudukan Dan Pencatatan Sipil ( Dispencapil ) North Minahasa. Cogito Smart Journal, Vol 3, No., 222-229. 